\title{
Identification of sources of resistance against boll rot complex of cotton
}

\author{
M. Nanda and V. R. Kulkarni* \\ Department of Plant Pathology, University of Agricultural Sciences, Dharwad (Karnataka) India \\ (Email: kulkarnivr@uasd.in)
}

\begin{abstract}
One hundred and eighteen genotypes/varieties/ hybrids belonging to all four species of Gossypium viz., G. arboreum, G. herbaceum, G. barbadense and G. hirsutum were screened against boll rot complex disease under natural epiphytotic conditions at Agriculture Research Station, Dharwad farm, University of Agricultural Sciences, Dharwad during Kharif 2017. Among these 118 germplasm lines tested, one line of Gossypiumar boreum i.e., FDK 281 and two lines of G. herbaceum namely, ANGH-1607 and GShv 894/13 showed highly resistant reaction against the disease. In addition, five lines of G. arboreum (CNA 2031, DLSA 17, NDLA 3086, PBD 22, PSCANOI-46), eight lines each of G. herbaceum (DDh-11, DwDh-1601, DwDh-1602, GBhv-308, G Cot 23/ DDhc 11, GShv 898/13, GShv 907/13, Gvhv-767) and G. barbadense (ARBHB-1601, BCS-23-18-7, DB-1602, DHB-1601, GBHV-184, LAHB-1, RHB-1008, Suvin), five lines of G. hirsutum (ARBH- 813, LHDP3, NNDC-10, NNDC-21, NNDC-55) and five intrahirsutum (ATM, Bindas, Dr. Brent, DHH- 11, DHH- 263) hybrid lines showed moderately resistant reaction against boll rot. Out of four species, germplasm lines of $G$. herbaceum has showed better performance against the disease.
\end{abstract}

Key Words : Cotton, Boll rot complex, Resistant sources

View Point Article : Nanda, M. and Kulkarni, V.R. (2020). Identification of sources of resistance against boll rot complex of cotton. Internat. J. agric. Sci., 16 (1) : 86-90, DOI:10.15740/HAS/IJAS/16.1/86-90. Copyright@ 2020: Hind Agri-Horticultural Society.

Article History : Received : 17.10.2019; Revised : 16.11.2019; Accepted : 19.12.2019

* Author for correspondence: 